\title{
Coatings for the NuSTAR mission
}

\author{
Finn E. Christensen ${ }^{\mathrm{a}}$, Anders C.Jakobsen ${ }^{\mathrm{a}}$, Nicolai F. Brejnholt ${ }^{\mathrm{a}}$, Kristin K Madsen ${ }^{\mathrm{b}}$, Allan \\ Hornstrup $^{\mathrm{a}}$, Niels J.Westergaard ${ }^{\mathrm{a}}$, Joan Momberg ${ }^{\mathrm{a}}$, Jason Koglin ${ }^{\mathrm{c}}$, Anne M. Fabricant ${ }^{\mathrm{c}}$, \\ Marcela Stern ${ }^{\mathrm{c}}$, William W. Craig ${ }^{\mathrm{d}}$, Michael J. Pivovaroff ${ }^{\mathrm{d}}$, David Windt ${ }^{\mathrm{e}}$
}

\author{
${ }^{a}$ Danish Technical University, National Space Institute,(DTU-Space), Copenhagen, Denmark \\ ${ }^{\mathrm{b}}$ Space Radiation Laboratory, California Institute of Technology, Pasadena, CA \\ ${ }^{\mathrm{c}}$ Columbia University, New York, NY \\ ${ }^{\mathrm{d}}$ Lawrence Livermore National Laboratory, Livermore, CA, \\ ${ }^{\mathrm{e}}$ Reflective X-ray Optics LLC, New York, NY
}

\begin{abstract}
The NuSTAR mission will be the first mission to carry a hard X-ray $(5-80 \mathrm{keV})$ focusing telescope to orbit. The optics are based on the use of multilayer coated thin slumped glass. Two different material combinations were used for the flight optics, namely $\mathrm{W} / \mathrm{Si}$ and $\mathrm{Pt} / \mathrm{C}$. In this paper we describe the entire coating effort including the final coating design that was used for the two flight optics. We also present data on the performance verification of the coatings both on $\mathrm{Si}$ witness samples as well as on individual flight mirrors.
\end{abstract}

Keywords: Multilayer coatings, Slumped glass, Hard X-ray optics, Calibration, NuSTAR

\section{INTRODUCTION}

The NuSTAR mission ${ }^{1,2}$ is a NASA small explorer mission scheduled for launch February 2012. It will carry two hard X-ray telescopes to orbit. It will provide a 100-fold increase in sensitivity over previous missions in this energy band and essentially open a new observational frontier in high energy astrophysics. The telescopes are based on the use of depth graded $^{3}$ multilayer coated segmented slumped glass ${ }^{4,5}$. The NuSTAR flight optics were completed in early March 2011 and underwent ground calibration in March 2011 at the Columbia University - RaMCaF facility ${ }^{6}$. The first results of the ground calibration are published in these proceedings ${ }^{7}$ and details of the fabrication including the precision mounting, metrology, qualification and environmental testing and integration and alignment on the spacecraft is also described in these proceedings ${ }^{8}$

The optic is a segmented and highly nested conical approximation to a Wolter I geometry with a focal length of $10.15 \mathrm{~m}$. Each optic contains 2376 pieces of multilayer coated D263 Schott glass. The glass is $0.21 \mathrm{~mm}$ thick and is produced in custom production runs at the Schott down draw facility in Grunenplan, Germany. There are 133 concentric shells in each optic. Individual substrates span $30^{\circ}$ (layers 69-133) or $60^{\circ}$ (layers 1-68) and have radii ranging from $54.4 \mathrm{~mm}$ to $191 \mathrm{~mm}$. The length of each mirror segment along the optical axis is $225 \mathrm{~mm}$. More details of the telescope design and geometry are given elsewhere ${ }^{7,9}$. Pt/C coatings were used on layers 1-89 and W/Si coatings were used on layers 90-133 for the two flight optics. A third complete optic was produced which used $\mathrm{Pt} / \mathrm{SiC}$ instead of $\mathrm{Pt} / \mathrm{C}$. A total of 10 recipes were chosen. Of these 7 are $\mathrm{Pt} / \mathrm{C}(\mathrm{SiC})$ recipes and 3 are $\mathrm{W} / \mathrm{Si}$ recipes. The design was based on a power law progression of the bilayer thicknesses, with the added inclusion of a top bilayer with increased thickness of the heavy reflecting layer. This facilitated a smooth transition between the total external reflection region and the Bragg reflection of the deeper layers in the stack. In 2009 we published the NuSTAR design recipes ${ }^{10}$, which at the time were based on the use of $\mathrm{Pt} / \mathrm{SiC}$ for the first 7 recipes. For the two flight optics we have updated the final design changing from $\mathrm{Pt} / \mathrm{SiC}$ to $\mathrm{Pt} / \mathrm{C}$. The change from using $\mathrm{C}$ instead of $\mathrm{SiC}$ was the result of testing of flight coatings on $\mathrm{Si}$ witness samples at hard $\mathrm{X}$-rays

Optics for EUV, X-Ray, and Gamma-Ray Astronomy V, edited by Stephen L. O'Dell, Giovanni Pareschi, Proc. of SPIE Vol. 8147, 81470U · (C) 2011 SPIE · CCC code: 0277-786X/11/\$18 - doi: 10.1117/12.894615 
at the Brookhaven synchrotron which showed increased roughness developing through the stack - an effect which had not previously been detected in the thinner calibration and qualification coatings.

The paper is organized as follows. The next section gives an overview of the total coating effort with references to the coating facility descriptions. This is followed by a section on the updated coating designs describing the constraints that were imposed or chosen. After this we present a section on the measurement and qualification of both Si witness samples and flight mirrors. This includes measurements of roughness of the bare substrates as well as qualification/calibration multilayer coatings on both types of substrates. This sets the stage for a section on the qualification of the production coating runs where we present data and a complete overview of all the hard X-ray data from all the Si witness samples from every coating run as well as hard X-ray data from a set of individual flight mirrors. Finally we present a section on data from the uniformity mapping in the DTU coating chamber and an overview of stress values from all the coating runs.

\section{COATING OVERVIEW}

As described above a total of 3 complete optics were produced. The spare optic has $\mathrm{Pt} / \mathrm{SiC}$ and $\mathrm{W} / \mathrm{Si}$ coatings and the two flight optics has $\mathrm{Pt} / \mathrm{C}$ and $\mathrm{W} / \mathrm{Si}$ coatings. The coatings for the spare optic were produced in the planar magnetron sputtering facility at DTU-Space in the time period from May 2009 to June 2010. A total of 155 flight coatings were performed in this period. Subsequently the coatings for the two flight optics FM1 and FM2 were produced in the period from July 2010 to February 2011. A total of 239 coating runs were used for the two flight optics. Due to the tight schedule for the build of the flight optics it was necessary to add extra coating capacity in this period in addition to the DTU facility. This was done by commissioning the planar magnetron sputtering facility at Reflective X-ray Optics LLC in New York to do $46 \mathrm{~W} / \mathrm{Si}$ coatings. For every flight coating we included on order 20 percent spares as breakage due to handling, cleaning and mounting could not be avoided. With the spares we coated a total of ca 8000 pieces for the three flight optics.

The Reflective X-ray Optics coating facility is described in [11]. For the NuSTAR coatings, the two $50 \mathrm{~cm}$ long magnetron cathodes (one for $\mathrm{W}$, one for $\mathrm{Si}$ ) were oriented vertically, facing outward. Glass shells, up to 24 per run, were mounted facing inward and were rotated about the two cathodes building up the multilayer one layer per pass. Custom baffles mounted between the cathodes and the shells were used to control coating uniformity.

The DTU facility and principle of operation is described in [12]. For the NuSTAR coatings we used 9 mounting plates. Each mounting plate could be subdivided into 3, 4 or 5 bays using separator plates. The number of bays depended on the azimuthal span of the flight pieces to be coated. The role of the separator plates was to provide collimation of the sputtered target material and at the same time secure the required coating uniformity over the surface of the coatings within a given coating run ${ }^{13}$. A picture of the inside of the coating chamber is shown below in figure 1 , where 4 bays are used on each mounting plate. All of the following discussions and descriptions are related to the DTU coating facility specifically. 


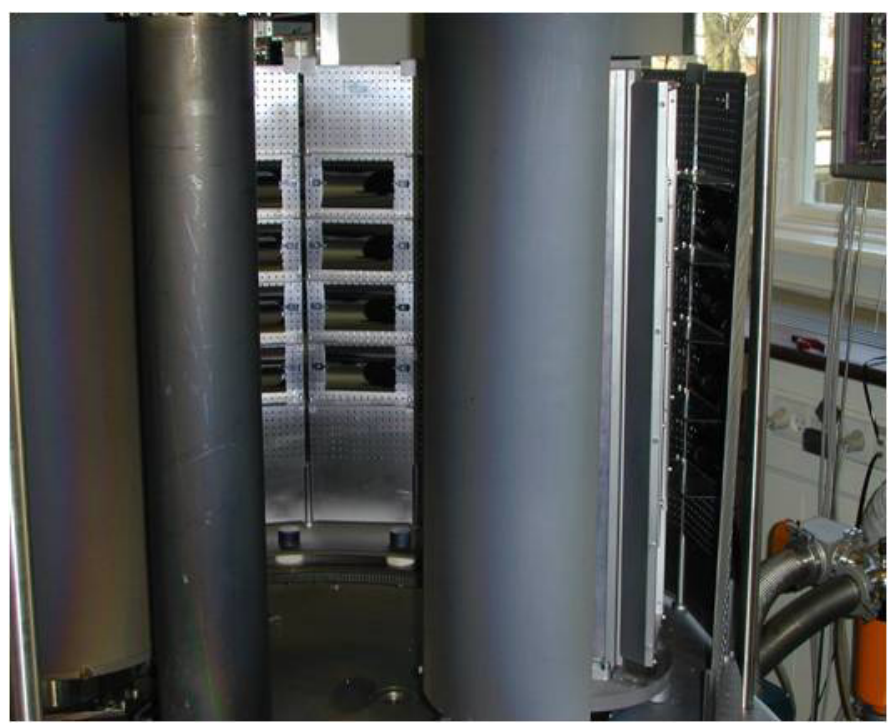

Figure 1: A look at the inside of the DTU NuSTAR coating chamber. 9 mounting plates carry from 3 to 5 mirror segments. In this photo there are 4 segments on each mounting plate.

We used 50.8 by $3.8 \mathrm{~cm}$ sputter cathodes obtained from Angstrom Sciences, Inc.. Previously we have found that we need to be sputtering at Ar pressures below 3 mTorr to get the optimum quality of coatings in the DTU facility ${ }^{13}$. We ran all the flight coatings for FM1 and FM2 at 2.8 mTorr. After an overall masking along the sputter targets established uniform coating rates along the targets, we adjusted the power settings to each of the targets such that the design value of the thickness of the heavy material relative to the bilayer thickness, the socalled $\Gamma$-parameter, was obtained for each of the material combinations. Subsequently we calibrated the bilayer deposition rates versus rotation speed of the ring holding the mounting plates. Initially we conducted frequent calibration runs to keep track of deposition rate drifting due to target wear etc. As we gained more experience we only did calibration runs for every 10-15 production runs. The coating rate of $\mathrm{Si}, \mathrm{SiC}$ and $\mathrm{C}$ is low compared to both $\mathrm{W}$ and Pt. This necessitated the use of two targets of the light material in order to meet the required $\Gamma$ value within a reasonable total coating time. The distance between the target and the surface of the mirror elements is $11 \mathrm{~cm}$. For Pt/C we used power settings of 1100 Watts for the two $\mathrm{C}$ targets and $150 \mathrm{Watts}$ for the $\mathrm{Pt}$ target. For W/Si we used 900 Watts for the two Si targets and 860 Watts for the W target. With these settings a Pt/C coating run typically lasted 12 hours while a W/Si coating lasted 8 hours for the coating designs described in the next section. This allowed ample time for cleaning and maintenance as well as changing of substrates and pump-down time such that one coating run could be done in a 24 hour cycle.

After every coating run we measured the Si witness sample reflectance at the DTU $8 \mathrm{keV}$ facility ${ }^{14}$ This enabled us to catch any problems immediately and take proper action. It also provided us with a check on the day to day drifting of coating rates and we were able to make small adjustments accordingly for the following coating run. Hence we were able to keep an average of close to one coating run per day for the 193 consecutive coating runs conducted in the DTU facility for FM1 and FM2. With the very tight coating schedule we usually sent the coated flight substrates off to Columbia University for immediate mounting in the optics but we did initially measure a few of the flight mirrors from every coating run at $8 \mathrm{keV}$ to check that the quality of the coating was similar to the $\mathrm{Si}$ witness sample. The $8 \mathrm{keV}$ data is not the same as a proper check of the actual reflectivity obtained at hard X-rays. This had to await that time was available at the RaMCaF facility in connection with the calibration campaign and data from this is presented in this paper. We were able, however, to do a few sanity checks at the Brookhaven Synchrotron at monochromatic energies of 50 and $60 \mathrm{keV}$. Here we found the roughness increase through the stack from the $\mathrm{Pt} / \mathrm{SiC}$ coatings which led us to using $\mathrm{C}$ instead of $\mathrm{SiC}$. 


\section{COATING DESIGN}

The development of an optimized coating design for NuSTAR follows the method used for the HEFT balloon mission ${ }^{15}$. This employs both a Field Of View (FOV) and energy weighted Figure of Merit (FOM) which balances the on- and offaxis area given the chosen telescope design. In case of the NuSTAR telescopes we chose to have additional spacing between shells to facilitate improved off-axis response on expense of a slightly lower on-axis area ${ }^{9}$. All the coatings for the HEFT mission were $\mathrm{W} / \mathrm{Si}$ which cut the effective area at the $\mathrm{W}-\mathrm{K}$ edge of $69.5 \mathrm{keV}$. For the NuSTAR mission we decided to add Pt-based coatings to extend the throughput to $78.4 \mathrm{keV}$, the Pt-K edge. Initial coating tests using both $\mathrm{Pt} / \mathrm{SiC}$ and $\mathrm{Pt} / \mathrm{C}$ provided very similar performance in terms of both the minimum attainable bilayer thickness and the all important interfacial roughness. Since the coating rate of $\mathrm{SiC}$ is twice that of $\mathrm{Pt} / \mathrm{C}$ it was initially decided to base the coating design of the NuSTAR telescopes on the use of $\mathrm{Pt} / \mathrm{SiC}$ and $\mathrm{W} / \mathrm{Si}$. It was found that dividing the radial range into 10 mirror groups was sufficient to optimize the FOM and no net gain could be obtained by adding more mirror groups considering the foreseeable uniformity and absolute bilayer thickness accuracy. Based on this, with the added consideration of a special design for the top bilayer as described before, a NuSTAR coating design was produced in $2009^{10}$. For both $\mathrm{Pt} / \mathrm{C}$ and $\mathrm{Pt} / \mathrm{SiC}$ the coating development had established that a minimum bilayer thickness, $\mathrm{d}_{\min }$ of 29 $\AA$ was a balanced choice for the design. Likewise we had established during the HEFT project that $25 \AA$ could be safely used for $\mathrm{W} / \mathrm{Si}$. The next section provides detailed data on this for $\mathrm{Pt} / \mathrm{C}$ and $\mathrm{W} / \mathrm{Si}$. We have also found that a reasonable trade-off between total coating thickness and coating time versus performance is obtained if the ratio between the interfacial roughness and bilayer period, $\sigma / \mathrm{d}$ is less than $\sim 1 / 6$; this is fulfilled with the above choice of minimum $\mathrm{d}$. This left us with the number of bilayers, $\mathrm{N}$, the power in the power law progression, $\mathrm{c}$, the maximum thickness of the topmost bilayer in the stack, $\mathrm{d}_{\max }$ and the $\Gamma$ value for the stack, $\Gamma_{\text {stack }}$ and the $\Gamma$ value for the top bilayer, $\Gamma_{\text {top }}$ as the design parameters for every mirror group under the important condition that a coating run should last no longer than 12 hours such that a 24 hour cycle could be maintained throughout the production coating. With these constraints we generated the 2009 coating designs shown in table 1 . This was subsequently used for the first telescope which became the spare telescope.

Table 1: 2009 NuSTAR multilayer design

\begin{tabular}{|r|r|r|r|r|r|r|r|r|r|r|r|}
\hline Group & Material & $\begin{array}{l}\text { Angle } \\
{[\mathrm{mrad}]}\end{array}$ & $\begin{array}{l}\text { Layer } \\
\text { range }\end{array}$ & $\begin{array}{l}\mathrm{D}_{\min } \\
{[\AA]}\end{array}$ & $\begin{array}{l}\mathrm{D}_{\max } \\
{[\AA]}\end{array}$ & $\mathrm{N}$ & $\mathrm{C}$ & $\begin{array}{l}\sigma \\
{[\AA]}\end{array}$ & $\Gamma_{\text {Top }}$ & $\Gamma_{\text {stack }}$ & $\begin{array}{l}\mathrm{D}_{\text {stack }} \\
{[\mu \mathrm{m}]}\end{array}$ \\
\hline 1 & $\mathrm{Pt} / \mathrm{SiC}$ & $\begin{array}{r}1.34- \\
1.52\end{array}$ & $1-12$ & 31.7 & 128.1 & 150 & 0.245 & 4.5 & 0.7 & 0.45 & 0.631 \\
\hline 2 & $\mathrm{Pt} / \mathrm{SiC}$ & -1.73 & $13-24$ & 30.5 & 120.9 & 150 & 0.228 & 4.5 & 0.7 & 0.45 & 0.611 \\
\hline 3 & $\mathrm{Pt} / \mathrm{SiC}$ & -1.96 & $25-36$ & 29.0 & 119.5 & 155 & 0.234 & 4.5 & 0.7 & 0.45 & 0.592 \\
\hline 4 & $\mathrm{Pt} / \mathrm{SiC}$ & -2.22 & $37-49$ & 29.0 & 118.2 & 155 & 0.214 & 4.5 & 0.7 & 0.45 & 0.578 \\
\hline 5 & $\mathrm{Pt} / \mathrm{SiC}$ & -2.52 & $50-62$ & 29.0 & 107.8 & 155 & 0.225 & 4.5 & 0.7 & 0.45 & 0.575 \\
\hline 6 & $\mathrm{Pt} / \mathrm{SiC}$ & -2.85 & $63-76$ & 29.0 & 103.3 & 155 & 0.225 & 4.5 & 0.7 & 0.45 & 0.586 \\
\hline 7 & $\mathrm{Pt} / \mathrm{SiC}$ & -3.23 & $77-89$ & 29.0 & 98.8 & 155 & 0.212 & 4.5 & 0.7 & 0.45 & 0.577 \\
\hline 8 & $\mathrm{~W} / \mathrm{Si}$ & -3.67 & $90-104$ & 25.0 & 95.2 & 291 & 0.238 & 4.3 & 0.8 & 0.38 & 0.955 \\
\hline 9 & $\mathrm{~W} / \mathrm{Si}$ & -4.16 & $105-118$ & 25.0 & 83.9 & 291 & 0.220 & 4.3 & 0.8 & 0.38 & 0.934 \\
\hline 10 & $\mathrm{~W} / \mathrm{Si}$ & -4.72 & $119-133$ & 25.0 & 74.5 & 291 & 0.190 & 4.3 & 0.8 & 0.38 & 0.902 \\
\hline
\end{tabular}

The coating development of $\mathrm{Pt} / \mathrm{SiC}$ was based on constant-d coatings with a relatively low number of bilayers and initial flight recipes for the inner mirror groups which did not exceed a total thickness of 0.3 micron. The final coating designs had significantly thicker coatings, as can be seen in table 1 . Well into the production coating for the first optic we got time at the Brookhaven synchrotron to measure the reflectance of the flight recipes on $\mathrm{Si}$ witness samples, for $\mathrm{Pt} / \mathrm{SiC}$ and $\mathrm{W} / \mathrm{Si}$ as well as for a similar test coating of $\mathrm{Pt} / \mathrm{C}$. The tests revealed, to our surprise, that the $\mathrm{Pt} / \mathrm{SiC}$ coatings had lower reflectance than expected from our coating design. This could only be explained by increased roughness building up through the stack. Later on the explanation was confirmed by reflectance measurements at the RaMCaF facility. The 
increased roughness also resulted in increased off-specular scatter for the $\mathrm{Pt} / \mathrm{SiC}$, and it would significantly affect the 80and $90 \%$ Power Diameters from the flight mirrors as well as leading to lower throughput. See data presented in section 5. Subsequent AFM data from the top surface of the $\mathrm{Pt} / \mathrm{SiC}$ coatings also revealed very significant roughness increase. On the other hand both the W/Si and Pt/C behaved as expected, and based on this we decided to use $\mathrm{Pt} / \mathrm{C}$ instead of $\mathrm{Pt} / \mathrm{SiC}$ for the next two optics which became the flight optics. A re-optimization following the same constraints as the first design was performed and resulted in the final coating design for the two flight optics shown in table 2 .

Table 2: Flight telescope multilayer design

\begin{tabular}{|r|r|r|r|r|r|r|r|r|r|r|r|}
\hline Group & Material & $\begin{array}{l}\text { Angle } \\
{[\mathrm{mrad}} \\
{[}\end{array}$ & $\begin{array}{l}\text { Layer } \\
\text { range }\end{array}$ & $\begin{array}{l}\mathrm{D}_{\min } \\
{[\AA]}\end{array}$ & $\begin{array}{l}\mathrm{D}_{\max } \\
{[\AA]}\end{array}$ & $\mathrm{N}$ & $\mathrm{C}$ & $\begin{array}{l}\sigma \\
{[\AA]}\end{array}$ & $\Gamma_{\text {Top }}$ & $\Gamma_{\text {stack }}$ & $\begin{array}{l}\mathrm{D}_{\text {stack }} \\
{[\mu \mathrm{m}]}\end{array}$ \\
\hline 1 & $\mathrm{Pt} / \mathrm{C}$ & $\begin{array}{r}1.34 \\
1.52\end{array}$ & $1-12$ & 29.0 & 133.7 & 145 & 0.245 & 4.5 & 0.7 & 0.45 & 0.558 \\
\hline 2 & $\mathrm{Pt} / \mathrm{C}$ & -1.73 & $13-24$ & 29.0 & 131.6 & 145 & 0.228 & 4.5 & 0.7 & 0.45 & 0.547 \\
\hline 3 & $\mathrm{Pt} / \mathrm{C}$ & -1.96 & $25-36$ & 29.0 & 129.6 & 145 & 0.234 & 4.5 & 0.7 & 0.45 & 0.551 \\
\hline 4 & $\mathrm{Pt} / \mathrm{C}$ & -2.22 & $37-49$ & 29.0 & 121.8 & 145 & 0.214 & 4.5 & 0.7 & 0.45 & 0.537 \\
\hline 5 & $\mathrm{Pt} / \mathrm{C}$ & -2.52 & $50-62$ & 29.0 & 109.5 & 145 & 0.225 & 4.5 & 0.7 & 0.45 & 0.541 \\
\hline 6 & $\mathrm{Pt} / \mathrm{C}$ & -2.85 & $63-76$ & 29.0 & 107.5 & 145 & 0.225 & 4.5 & 0.7 & 0.45 & 0.541 \\
\hline 7 & $\mathrm{Pt} / \mathrm{C}$ & -3.23 & $77-89$ & 29.0 & 102.8 & 145 & 0.212 & 4.5 & 0.7 & 0.45 & 0.534 \\
\hline 8 & $\mathrm{~W} / \mathrm{Si}$ & -3.67 & $90-104$ & 25.0 & 95.2 & 291 & 0.238 & 4.3 & 0.8 & 0.38 & 0.955 \\
\hline 9 & $\mathrm{~W} / \mathrm{Si}$ & -4.16 & $105-118$ & 25.0 & 83.9 & 291 & 0.220 & 4.3 & 0.8 & 0.38 & 0.934 \\
\hline 10 & $\mathrm{~W} / \mathrm{Si}$ & -4.72 & $119-133$ & 25.0 & 74.5 & 291 & 0.190 & 4.3 & 0.8 & 0.38 & 0.902 \\
\hline
\end{tabular}

\section{COATING AND SUBSTRATE QUALIFICATION}

We used double side super polished Si witness samples for every production coating run. The same Si substrates were used during the initial coating development and coating calibration and qualification. These samples were produced by Wacker Siltronic AG. They are 12 inch wafers of $0.775 \mathrm{~mm}$ thickness. We cut them to an appropriate size for X-ray testing (ca 100 by $20 \mathrm{~mm}$ ) and cleaned them using a series of ultrasonic baths. The cleaning process comprised an acidic soap bath and a running DI rinse followed by acetone and ethanol baths, another DI rinse, and finally blow-drying using dry Nitrogen. This produced consistently clean and super smooth surfaces for the coating qualification. The cleaning of the slumped glass substrates before and after slumping proved to be more difficult. Initially, during the production slumping for the first telescope - the one that became the spare telescope - an ultrasonic alkaline soap cycle was used to clean the flat glass before slumping. This proved to have a serious detrimental effect on the roughness of the glass as shown in figure 2, and was abandoned before the production slumping of the glass for the two flight telescopes. For these an acidic soap and/or DI rinse was used for the cleaning of the flat glass before slumping. The slumping process, which uses BN as a release layer between the slumping mandrel and the flight glass ${ }^{16}$ necessitated a two step cleaning process before coating. A manual pre-clean using acidic soap and ethanol was required to remove residue left from the slumping process before proceeding to an ultrasonic process identical to the one used for the Si wafers. Although not perfect this process resulted in slumped glass substrates of consistent cleanliness and roughness. Table 3 lists $8 \mathrm{keV}$ $\mathrm{X}$-ray data and AFM data from the Si witness samples, flat glass and slumped flight glass. It is clear that the Si samples have a smaller roughness than the glass. The roughness of both the flat glass and the slumped glass showed more variation than the $\mathrm{Si}$ witness samples and the rms variation is listed in the table for the $\mathrm{X}$-ray measurements. For the AFM data we only have a few measurements for each type of substrate but the trend is the same as for the X-ray measurements. 


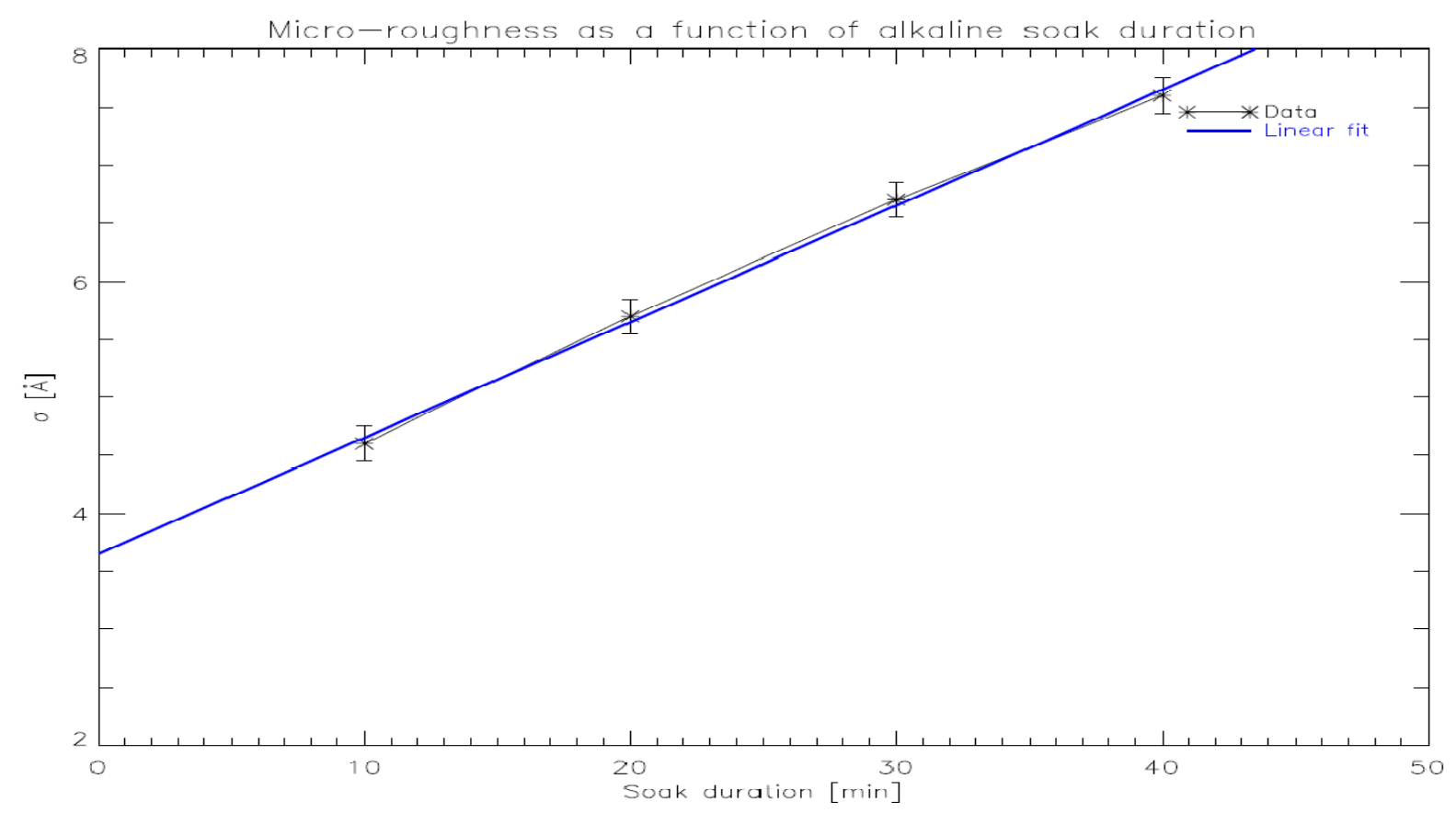

Figure 2: Measured roughness versus time in ultrasonic alkaline soap bath for a set of as-received flat glass samples. Note the roughness extrapolation to zero time is very close to the average roughness we have measured from flat glass using an acidic soap cleaning. See table 3 .

Table 3: Measured roughness from bare substrates

\begin{tabular}{|l|l|l|}
\hline Substrate & $\begin{array}{l}8 \mathrm{keV} \text { data } \\
\text { Up to } 2 \text { micron }\end{array}$ & $\begin{array}{l}\text { AFM } \\
20 \mathrm{~nm} \text { to 2 micron }\end{array}$ \\
\hline Si Witness & $2.8+-0.2 \AA$ & $1.0 \AA$ \\
\hline Flat Glass & $3.5+-0.5 \AA$ & $2.1 \AA$ \\
\hline Slumped Glass & $3.8+-0.5 \AA$ & $2-3.8 \AA$ \\
\hline
\end{tabular}

As noted in the previous section, we have found that effective depth graded multilayer coatings for this type of application need to have a ratio between the interfacial roughness and the smallest bilayer thickness, $\sigma / \mathrm{d}_{\min }$ less than $\sim 1 / 6$. The resulting minimum d-spacing is different for different material combinations and needs to be experimentally determined. To this end we produced a series of constant d-spacing coatings with 10 bilayers on Si substrates and measured the roughness using reflectometry at the DTU $8 \mathrm{keV}$ facility, as well as, using hard X-ray reflectometry at the $\mathrm{RaMCaF}$ facility. Figures 3 and 4 show the result of these measurements for $\mathrm{Pt} / \mathrm{C}$ and $\mathrm{W} / \mathrm{Si}$. 


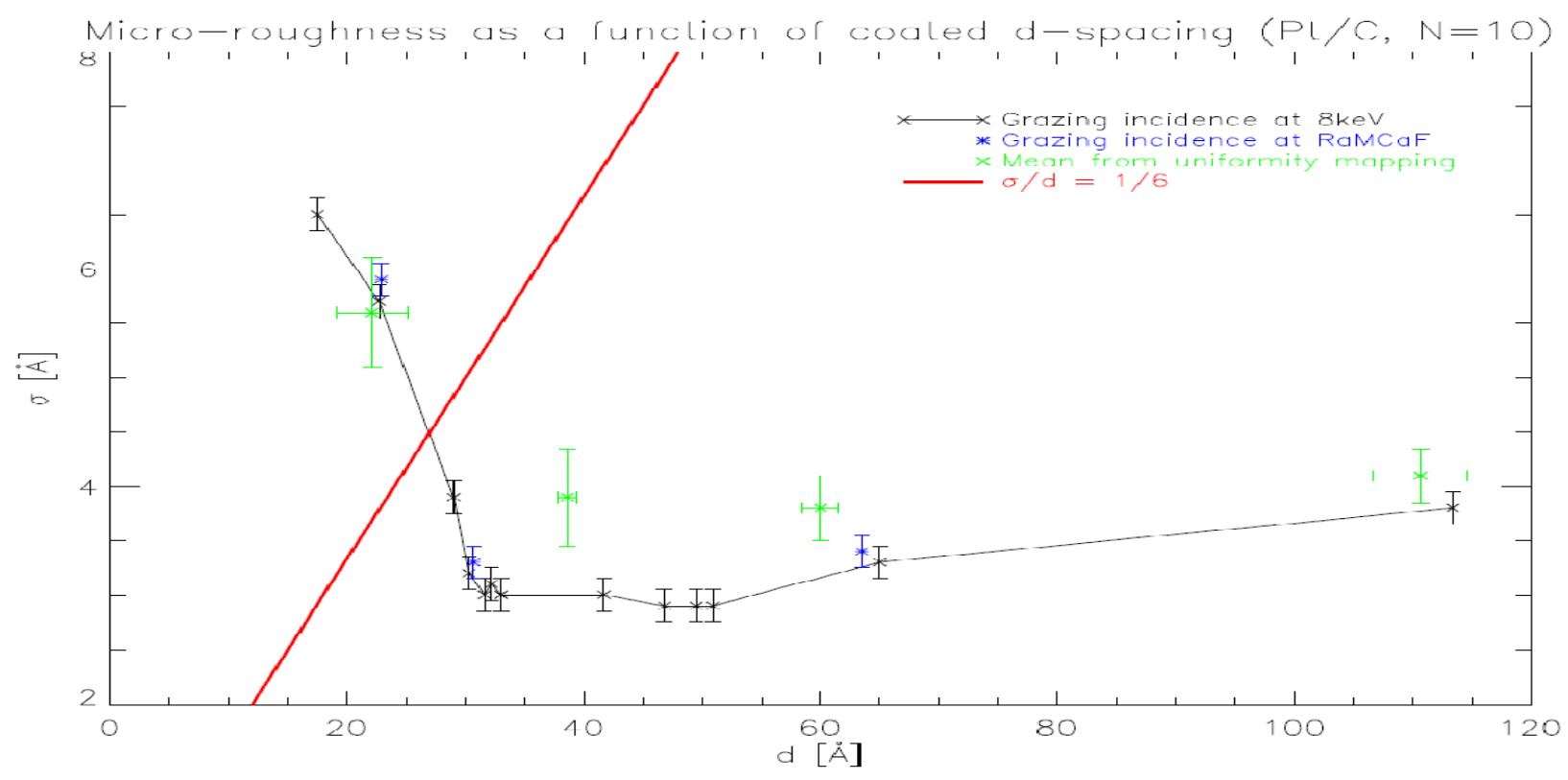

Figure 3: Measured roughness versus d-spacing for 10 bilayer constant period $\mathrm{Pt} / \mathrm{C}$ coatings. Both $8 \mathrm{keV}$ data and high energy RaMCaf data are shown from coatings on Si witness substrates and also data points from ca 100 measurements on constant period coatings on slumped glass uniformity samples. The spread in $\mathrm{d}$ for these is represented by the 'error' bar along the d-axis and the 'error' bar on the roughness represents the rms variation of the measured roughness. A line corresponding to the condition that $\sigma / \mathrm{d}$ is $1 / 6$ is also shown.

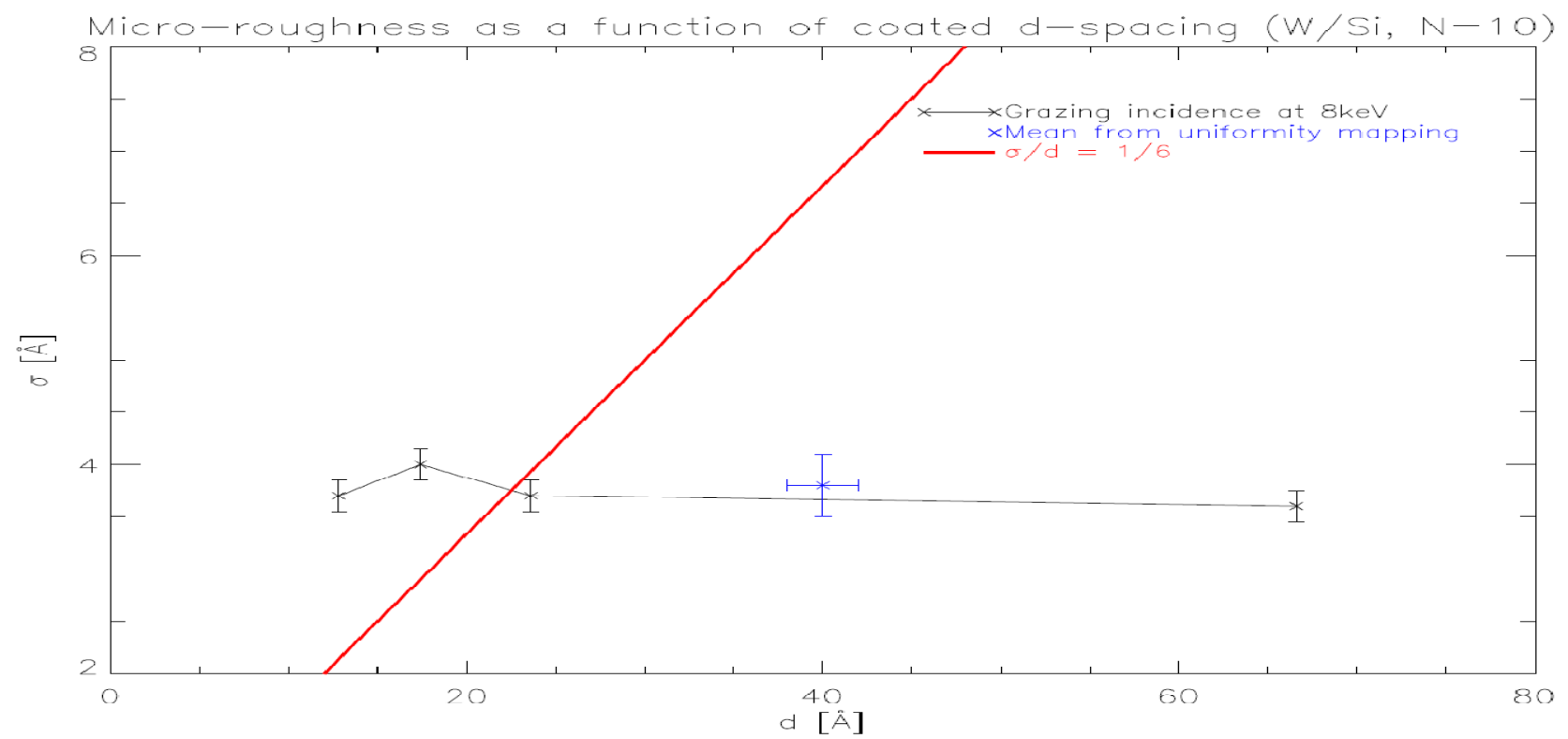

Figure 4: Same type of data as in figure 3 for W/Si. 
For Pt/C we observe low interfacial roughness similar to the underlying Si wafer roughness at d-spacings down to ca 30 $\AA$. At lower d-spacings a significant increase of the roughness takes place and as consequence we chose $29 \AA$ as the minimum d-spacing for the $\mathrm{Pt} / \mathrm{C}$ designs (similar data for the earlier $\mathrm{Pt} / \mathrm{SiC}$ data revealed the same behavior and $29 \AA$ was chosen here as well). This still leaves some margin before running into the limit of $\sigma / d=1 / 6$. In the same plot we show both $8 \mathrm{keV}$ DTU data and some high energy data from the RaMCaF facility. The latter tend to give a little higher roughness. This is consistent with the length scales probed. At the $8 \mathrm{keV}$ DTU facility the roughness is from length scales up to 2 micron whereas at RaMCaF it is on length scales up to 10 micron. We also show the average roughness found from ca 100 measurements of constant d-spacing coatings on slumped glass from uniformity mapping samples. It is obvious that the roughness from these is higher than that of the Si wafers, consistent with the difference in substrate roughness listed in table 3. For W/Si we do not observe a sharp increase of the roughness at d-spacings as low as $15 \AA$. Nevertheless to stay on the right side of $\sigma / d$ as shown by the red line with some margin, we chose a $d_{\min }$ of $25 \AA$ for the $\mathrm{W} / \mathrm{Si}$ designs.

\section{X-RAY QUALIFICATION OF SI WITNESS SAMPLES AND FLIGHT MIRRORS}

The set of witness samples from every coating run served to keep a day to day quality assurance on the coating runs. We were able to immediately measure the $8 \mathrm{keV}$ reflectance and keep track of significant deposition rate drifts and quality. An equally important purpose was to eventually measure the reflectance of all of these samples at high energies at the RaMCaF facility, such that these could be used directly as an input to the optics response model in combination with the coating chamber uniformity mapping described in the last section of this paper. For this to work properly we also need to measure, independently, the reflectance of a representative set of flight mirrors at high energies, such that the previously measured higher roughness of the slumped glass relative to the witness samples can be quantified directly on coated flight mirrors.

The same holds true for the high energy scattering from Si witness samples and flight mirrors. From the first results of the calibration campaign of FM1 and FM2 there appears to be very little contribution to the telescope PSF from scattering $^{7}$ but it is still important to put accurate limits on this contribution by direct measurement. Once quantified this effect can subsequently be factored into future telescope designs of this type which will have Half Power

Diameters(HPD) specifications significantly lower than the 52 arcsec obtained for the NuSTAR telescopes ${ }^{7}$

At the time of writing we have completed the RaMCaF reflectance measurement of more than $90 \%$ of the Si Witness samples as well as a reasonably representative set of flight mirrors. We have also measured the high energy scatter at the Brookhaven synchrotron at monochromatic energies of 50 and $60 \mathrm{keV}$ from representative flight coatings on Si witness samples of all three material combinations used $-\mathrm{Pt} / \mathrm{SiC}, \mathrm{Pt} / \mathrm{C}$ and $\mathrm{W} / \mathrm{Si}$.

Figures 5-7 show RaMCaF reflectance data from Si witness samples from FM1 and FM2 production coating runs. The data shown in figures 5-7 are taken near $0.22 \mathrm{deg}$. The line is a fit to the data using a d-spacing progression with small but significant deviation from the design power law. The deviation turned out to be a general feature and especially important for the first 3-5 bilayers in the top of the stack. This is not surprising as this is where the d-spacings vary greatly from bilayer to bilayer and therefore is more difficult to calibrate accurately. Also, of course, absolute values of the d-spacings vary from coating run to coating run and is easily determined from these fits. Figures 8 and 9 show the design d-spacings and the as-coated d-spacings in the top and bottom of the stack from the recipe 2 data shown in figure 5. 


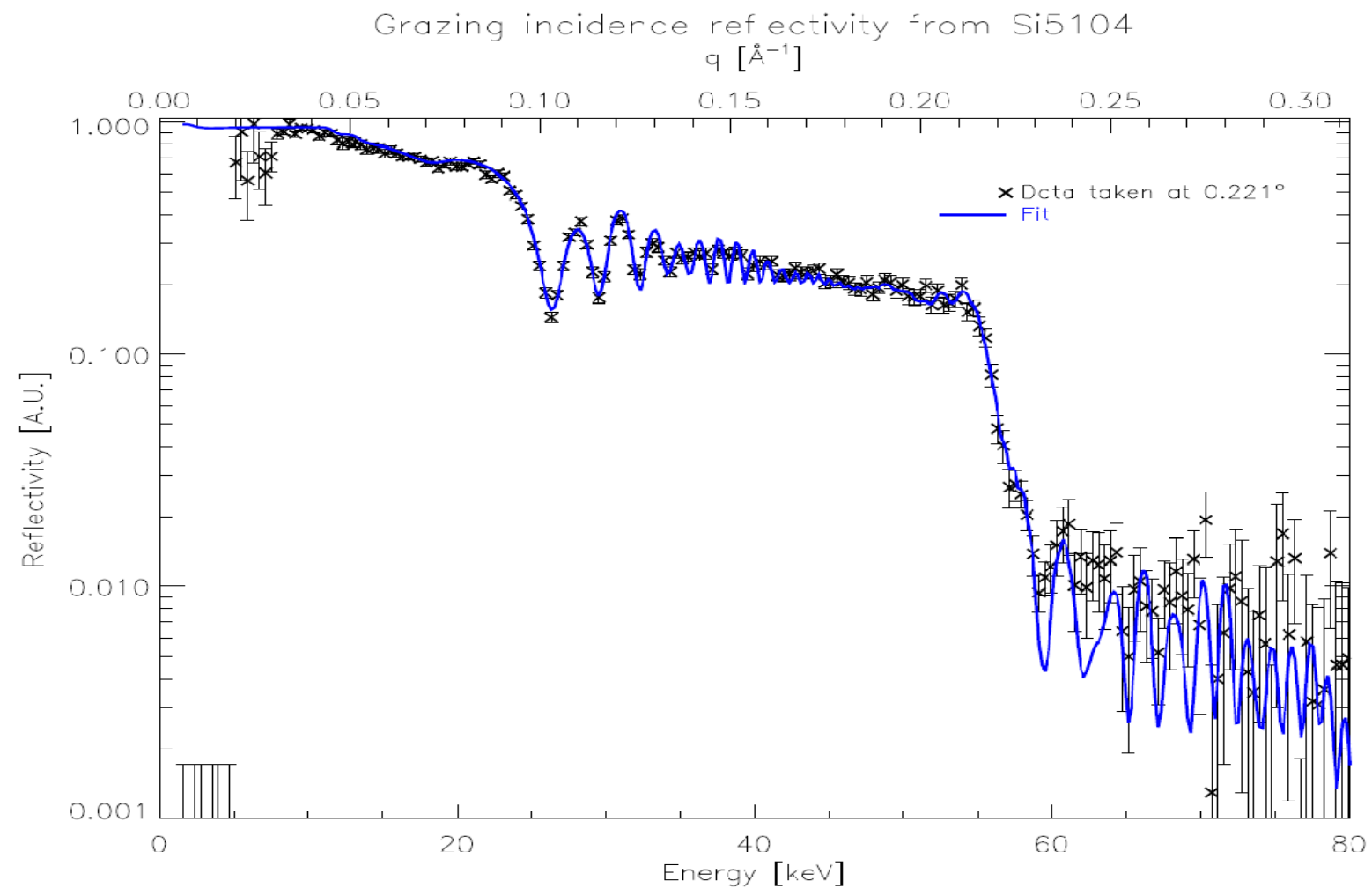

Figure 5 : RamCaF reflectance data for witness sample 5104. Flight recipe 2.

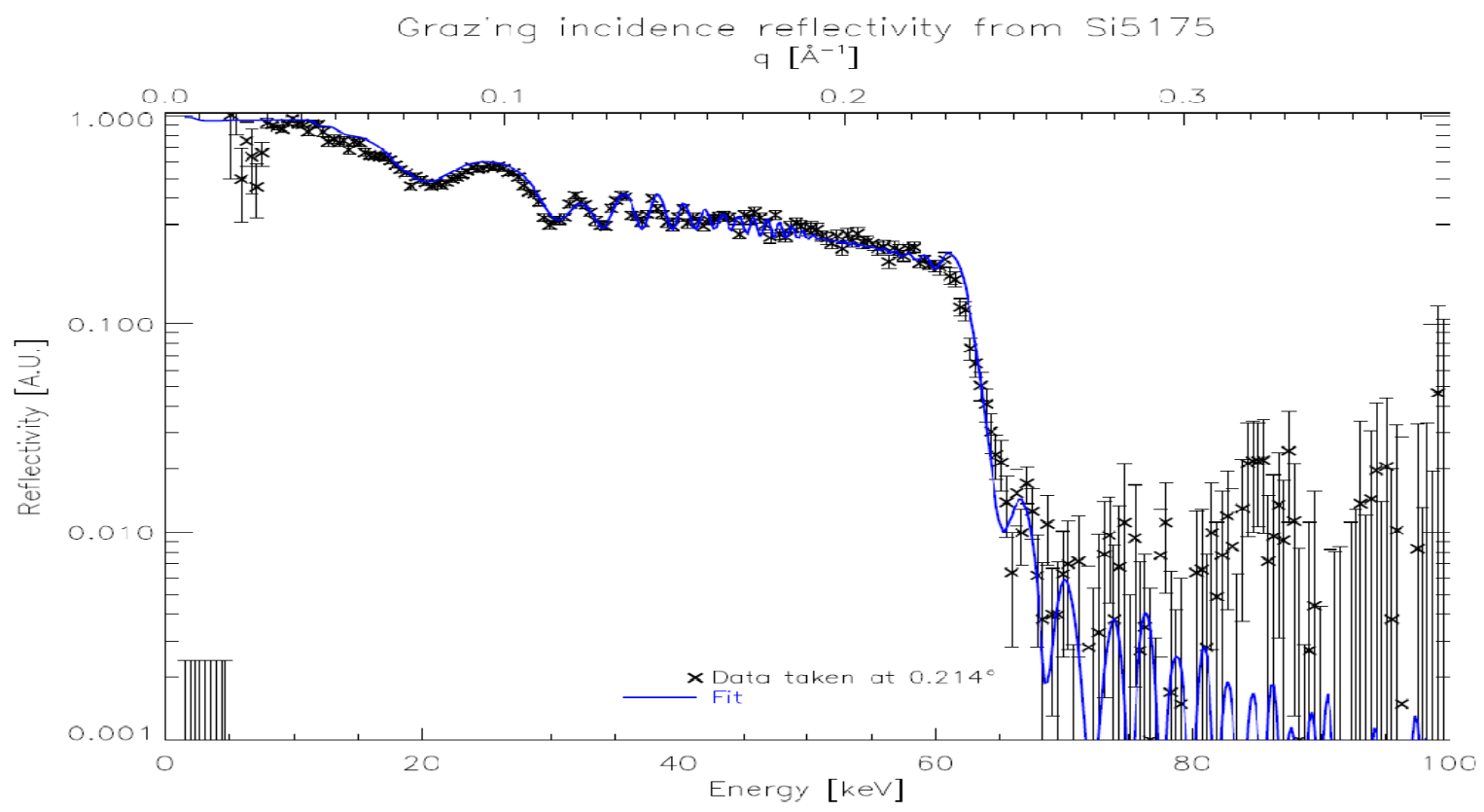

Figure $6:$ RaMCaF reflectance data for witness sample 5175. Flight recipe 6. 


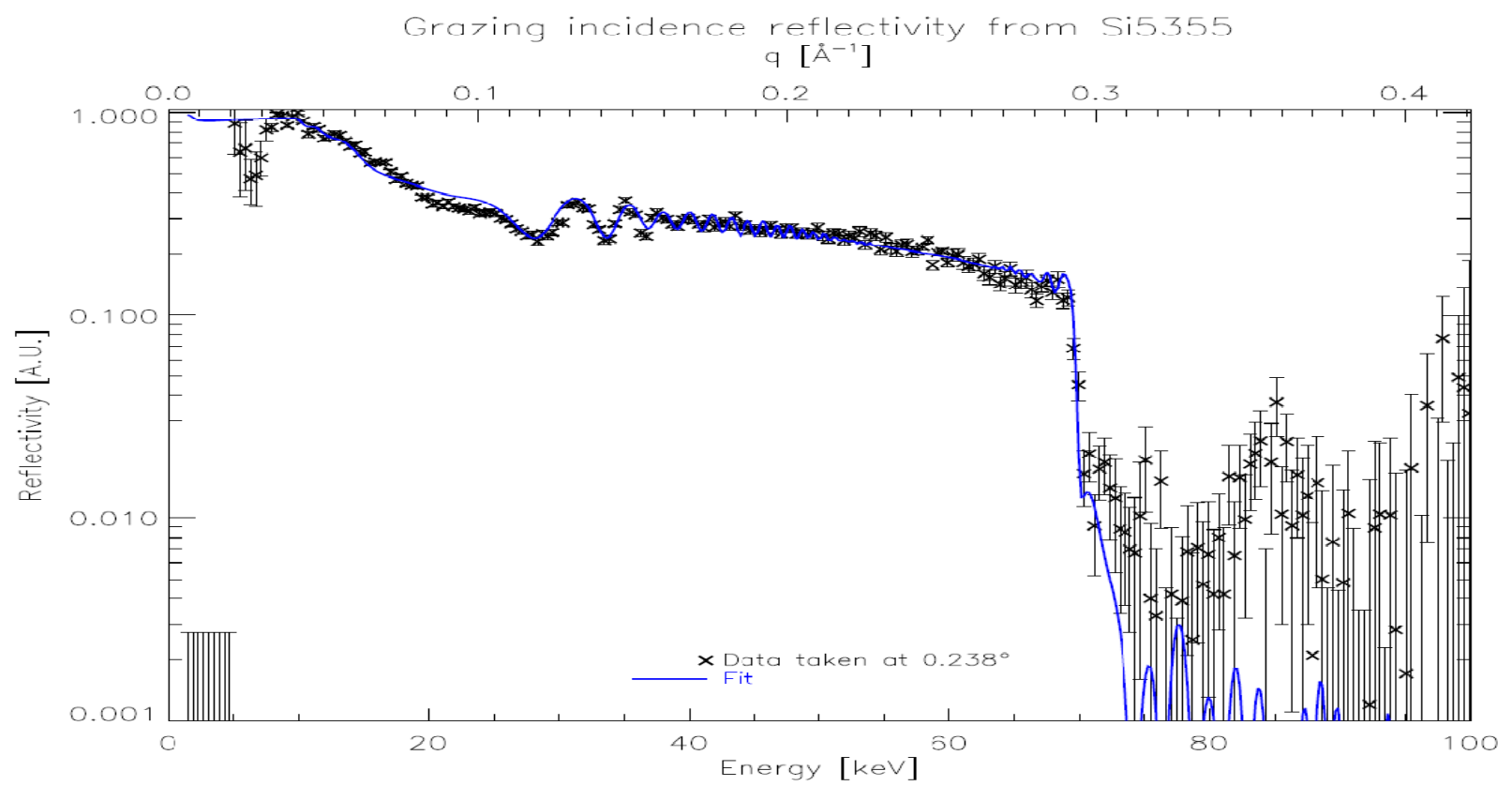

Figure $7: \mathrm{RaMCaF}$ reflectance data for witness sample 5355. Flight recipe 10 


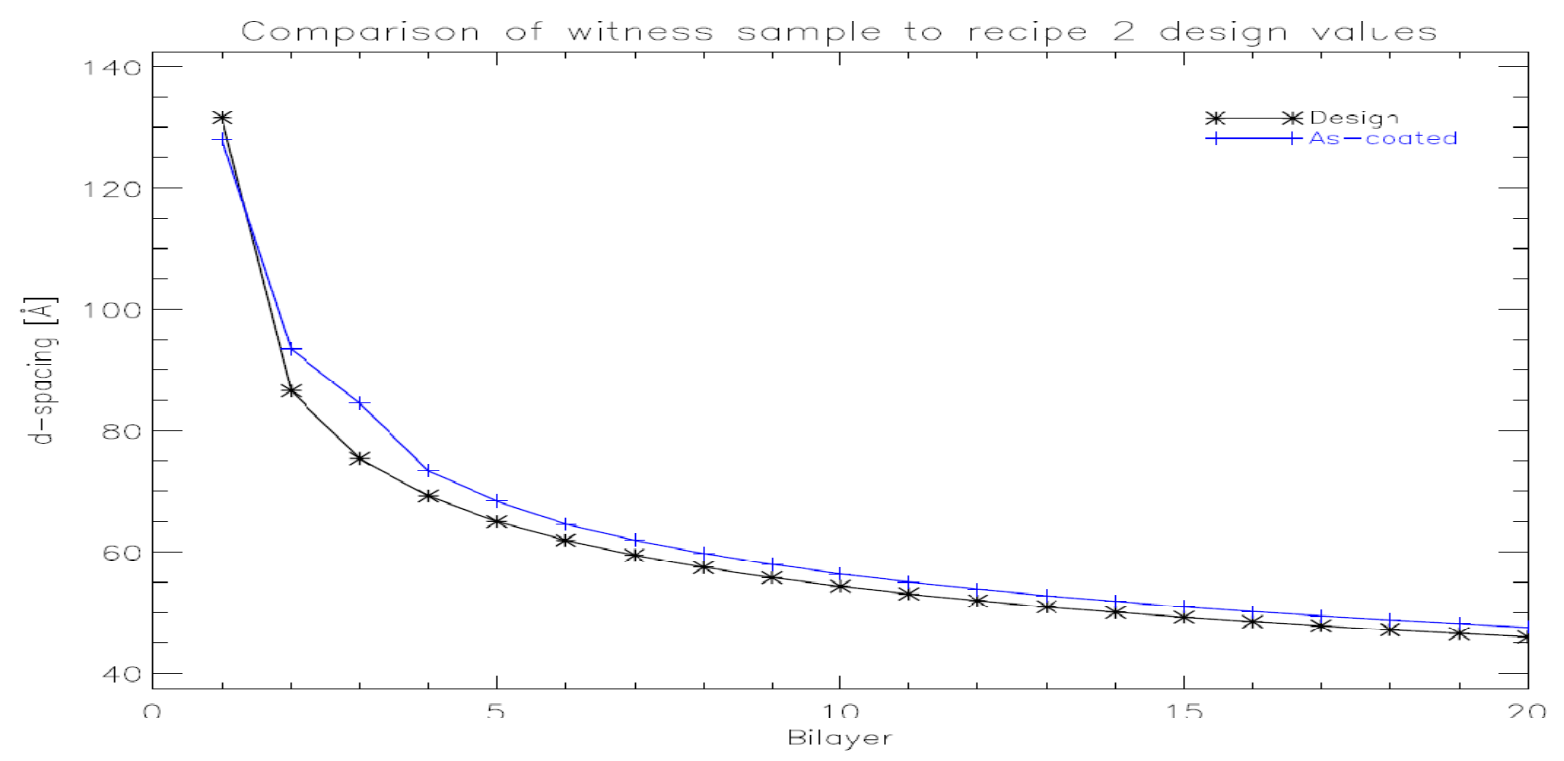

Figure $8: \mathrm{d}$-spacing progression for recipe 2 sample in figure 5 for the topmost bilayers.

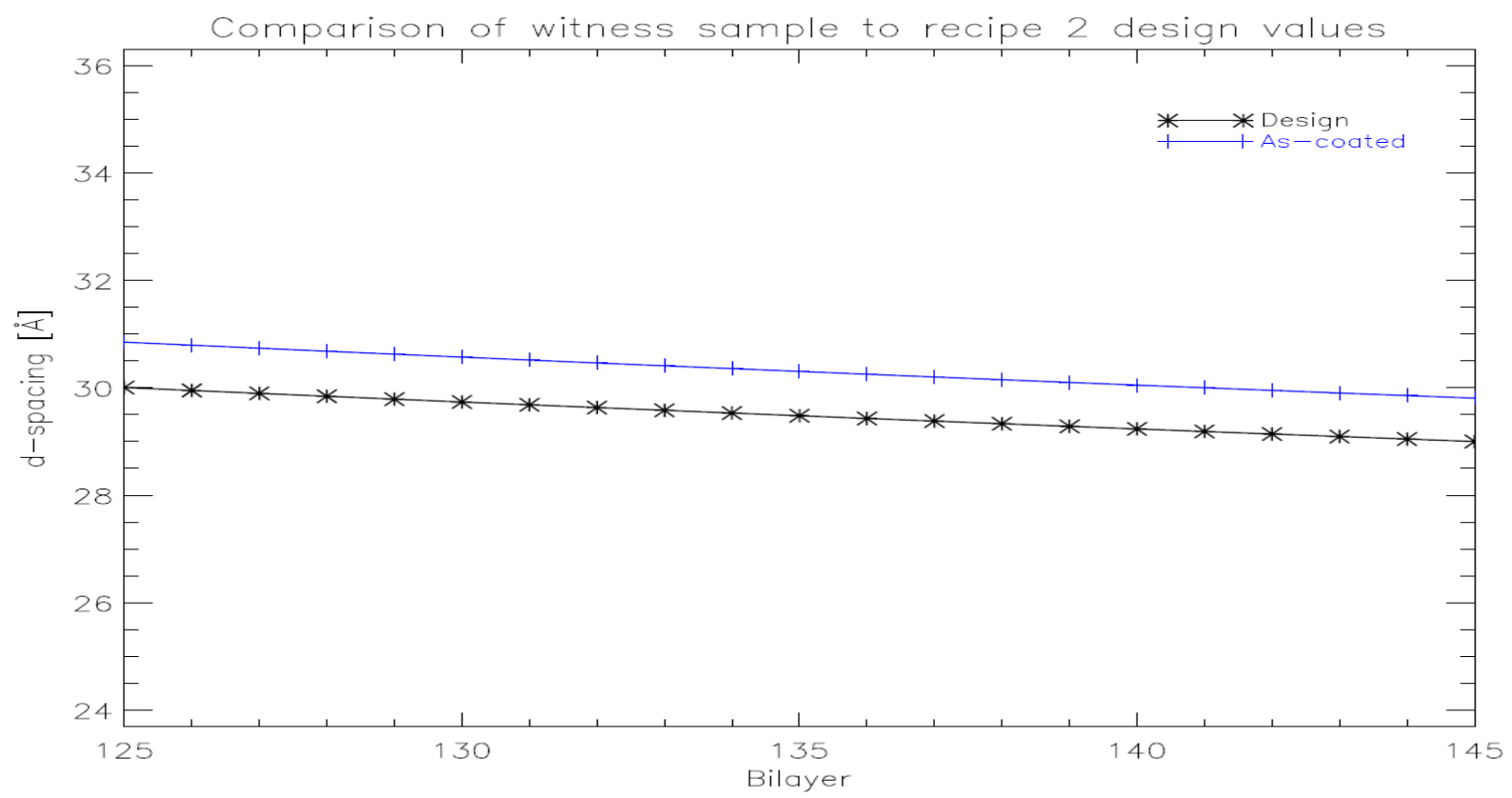

Figure $9: \mathrm{d}$-spacing progression for recipe 2 sample in figure 5 for the bottommost bilayers.

The data shown in figures 5-7 cut off at high energies naturally due to the $d_{\min }$ value. At energies below 10-12 keV there is a strong variation of the incoming intensity due to inherent line emission from the Tungsten source, the onset of absorption in the air gaps and residual pressure in the evacuated pipes. This makes the low-energy normalization of 
the reflected beam very uncertain due to redistribution in the Ge detector ${ }^{7}$. Since all the witness samples have been measured at $8 \mathrm{keV}$ at DTU we have an independent handle on the reflectance below $10 \mathrm{keV}$. An example of the 8 $\mathrm{keV}$ data is shown in figure 10. It is clear from this that theoretical reflectance is obtained below the critical angle of total external reflection, which is all that matters at $8 \mathrm{keV}$.

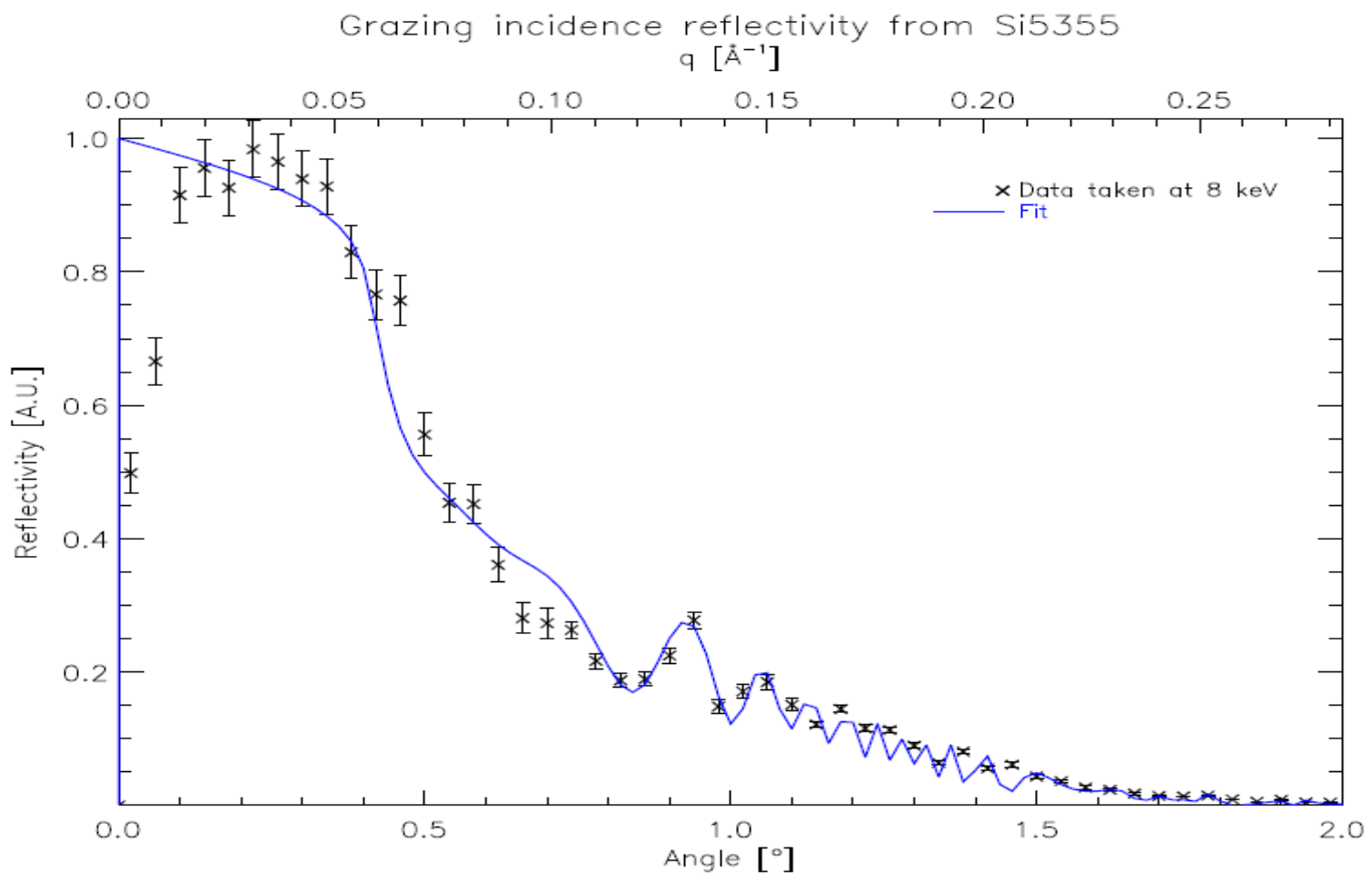

Figure 10:8 keV reflectance data from witness sample 5355. Flight recipe 10. This is the same sample as the one shown in figure 7 and the line is the fit based on the parameters found from the RaMCaf data in figure 7.

Table 4 gives an overview of all the RaMCaF data from the Si witness samples by giving mean fit values for each recipe in table 2 along with the mean value of chi square for all the fits within a recipe group. Obviously the parameters come close to the design values. Overall $\mathrm{d}_{\min }$ is slightly lower than the designs, which is beneficial for the off-axis response and the high energy response. $d_{\min }$ is still high enough that we are not jeopardizing the roughness values, which are very close to the ones foreseen in the design. 
Table 4: Mean fit values of all Si witness samples.

\begin{tabular}{|l|l|l|l|l|l|l|l|l|}
\hline Recipe & \# of samples & $\chi^{2}$ & $\begin{array}{l}\mathrm{d}_{\min } \\
\AA\end{array}$ & $\begin{array}{l}\mathrm{d}_{\max } \\
\AA\end{array}$ & $\mathrm{C}$ & $\begin{array}{l}\Sigma \\
\AA\end{array}$ & $\Gamma_{\text {stack }}$ & $\Gamma_{\text {top }}$ \\
\hline 1 & 14 & 1.20 & 26.9 & 119.9 & 0.245 & 4.45 & 0.46 & 0.70 \\
\hline 2 & 15 & 0.98 & 28.3 & 131.5 & 0.245 & 4.63 & 0.45 & 0.71 \\
\hline 3 & 15 & 0.99 & 27.4 & 123.6 & 0.238 & 4.40 & 0.46 & 0.68 \\
\hline 4 & 17 & 1.01 & 27.3 & 113.0 & 0.217 & 4.39 & 0.45 & 0.68 \\
\hline 5 & 14 & 1.27 & 27.2 & 102.0 & 0.223 & 4.42 & 0.46 & 0.66 \\
\hline 6 & 23 & 1.03 & 26.8 & 99.8 & 0.225 & 4.33 & 0.46 & 0.65 \\
\hline 7 & 22 & 1.20 & 25.7 & 90.9 & 0.216 & 4.18 & 0.46 & 0.66 \\
\hline 8 & 5 & 2.02 & 23.4 & 87.6 & 0.246 & 4.17 & 0.40 & 0.74 \\
\hline 9 & 15 & 1.12 & 21.8 & 89.5 & 0.237 & 4.31 & 0.40 & 0.77 \\
\hline 10 & 7 & 0.87 & 21.9 & 78.0 & 0.202 & 4.32 & 0.40 & 0.74 \\
\hline
\end{tabular}

A RaMCaF data set from a flight mirror recipe 4 is shown in figure 11 . The data have been fitted in the same way as the $\mathrm{Si}$ witness samples. The thin flight mirrors are difficult to mount accurately and will typically not be as flat as the $\mathrm{Si}$ witness samples which are $0.775 \mathrm{~mm}$ thick and align easily using a flat vacuum chuck. Nevertheless we managed to mount the flight mirrors so that accurate measurements could be obtained. The roughness is higher than for the $\mathrm{Si}$ witness samples. The range measured for $9 \mathrm{Pt} / \mathrm{C}$ samples is $4.75-5.7 \AA$ with an average of $5.1 \AA$. The average of 3 $\mathrm{W} / \mathrm{Si}$ samples is $4.7 \AA$. This is in contrast to the $4.1-4.6 \AA$ for the Si witness samples. This again is completely consistent with the increased roughness we have measured both on the bare substrates as well as on constant d-spacing samples.

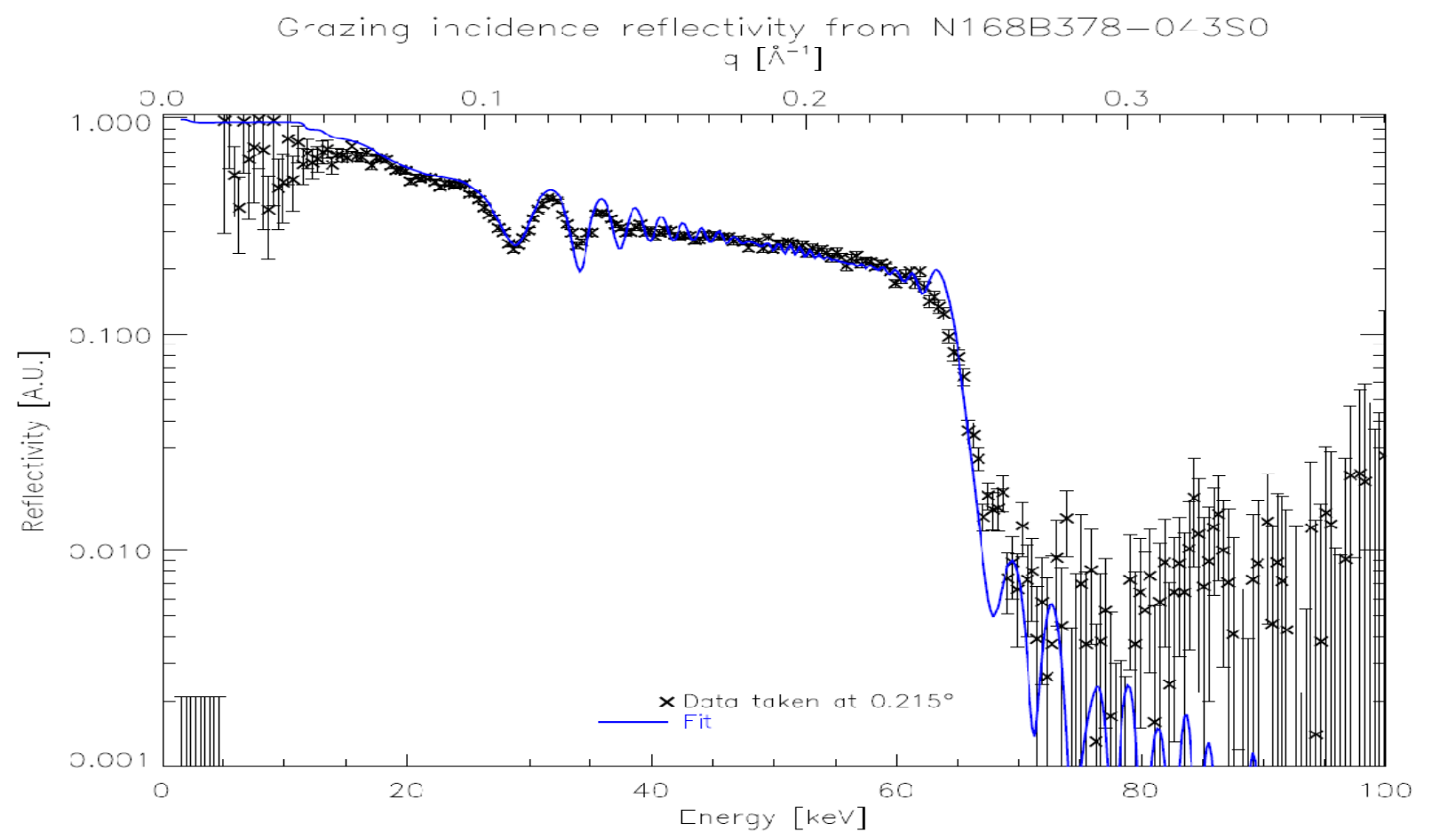

Figure $11: \mathrm{RaMCaF}$ reflectance data from a flight mirror - recipe 4 . The line is a fit which yields a roughness of 4.75 $\AA$. The smearing of the data relative to the model where the minimum d cuts the reflectance is due to figure error of the sample. 
In a handful of the 193 DTU flight coating we experienced small periods of time where one of the three sputter cathodes would drop out. This effect is clearly seen in the RaMCaF data from the relevant Si witness samples. An example is shown in figure 12, where the line is an attempted but obviously failed fit. Using the data from the witness samples the overall effect can be quantified and at any rate is a small second order effect on the throughput versus energy.

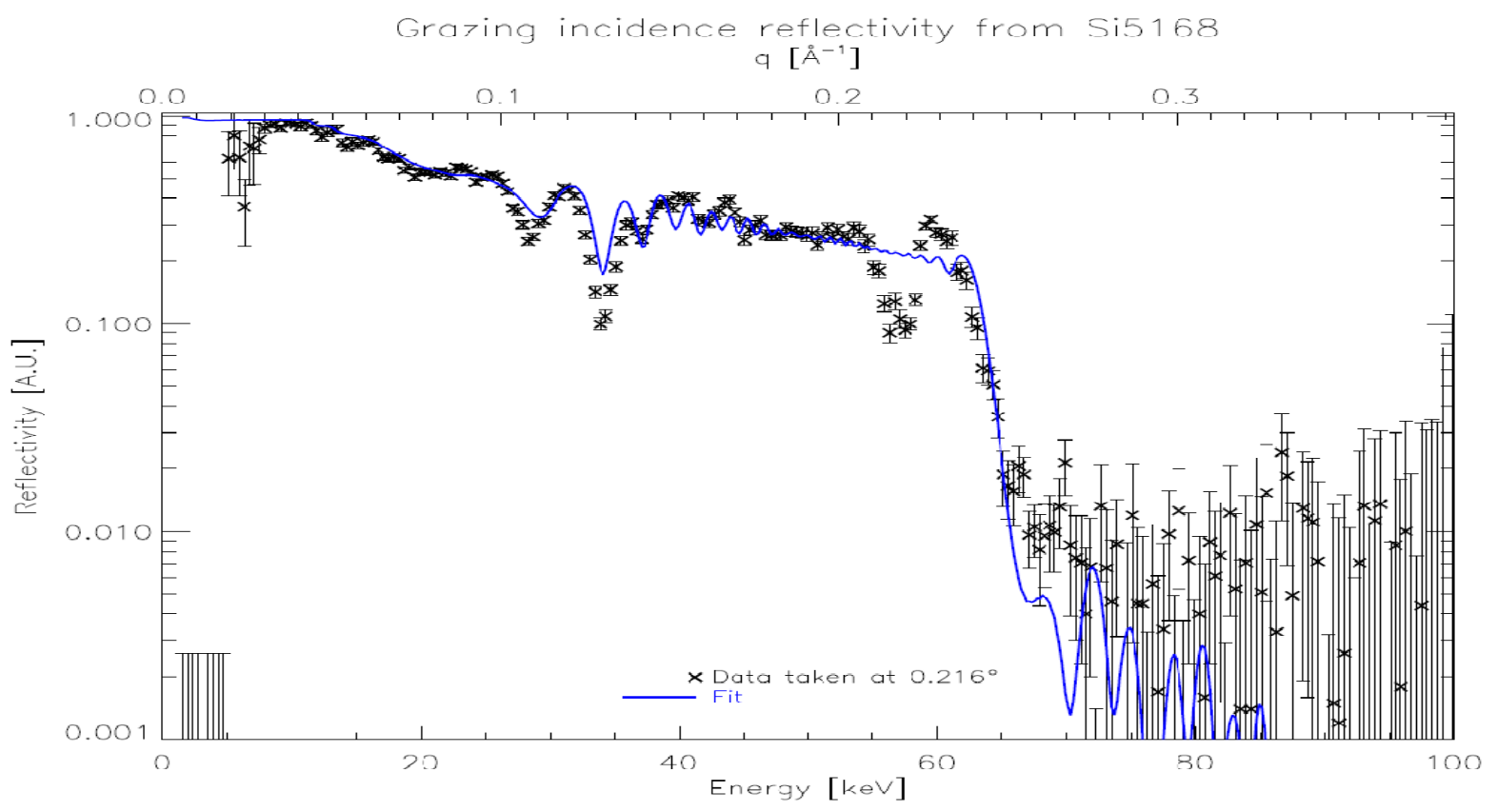

Figure 12 : RaMCaF reflectance data from witness sample 5168. Cathode drop out during coating is clearly visible in the structure versus energy.

Scatter data cannot be obtained at a low intensity source such as the RaMCaF facility, as 5-6 orders of dynamic range using a small footprint monochromatic beam are required to do this accurately. Therefore we have conducted scatter measurements at the Brookhaven synchrotron at the X17 beamline. This beamline can deliver monochromatic X-rays in the energy range of NuSTAR. Figure 13 show the reflectance versus graze angle at $50 \mathrm{keV}$ for a $\mathrm{Pt} / \mathrm{SiC}$, a Pt/C and a W/Si coating on $\mathrm{Si}$ witness substrates. Figure 14 show scatter data obtained at a graze angle where the entire multilayer stack is active in producing the reflection - that is above the critical angle of total external reflection. Outside the core of the specularly reflected beam there is obviously a significant level of scatter from the $\mathrm{Pt} / \mathrm{SiC}$ sample, but very little is observed for $\mathrm{Pt} / \mathrm{C}$ and $\mathrm{W} / \mathrm{Si}$. Likewise it is clear from the reflectance curves that the level of reflectivity is lower for $\mathrm{Pt} / \mathrm{SiC}$ than for $\mathrm{Pt} / \mathrm{C}$ and $\mathrm{W} / \mathrm{Si}$. Based on the $\mathrm{Pt} / \mathrm{C}$ and $\mathrm{W} / \mathrm{Si}$ data we have simulated the effect of the scatter contribution to the HPD and found that this is limited to a few arcsec and thus insignificant to a NuSTAR optic. With the higher roughness observed on the flight mirrors and a different surface topography it is required that we conduct the same scatter measurement on a set of flight mirrors. This has not yet been done but is planned for the near future. Before these data have been obtained we cannot completely rule out or quantify any scatter contribution to the NuSTAR PSF. We already have AFM data from the top surface of flight mirrors which we will use to correlate with the scatter measurements and produce a realistic scatter mode $^{17}$. 


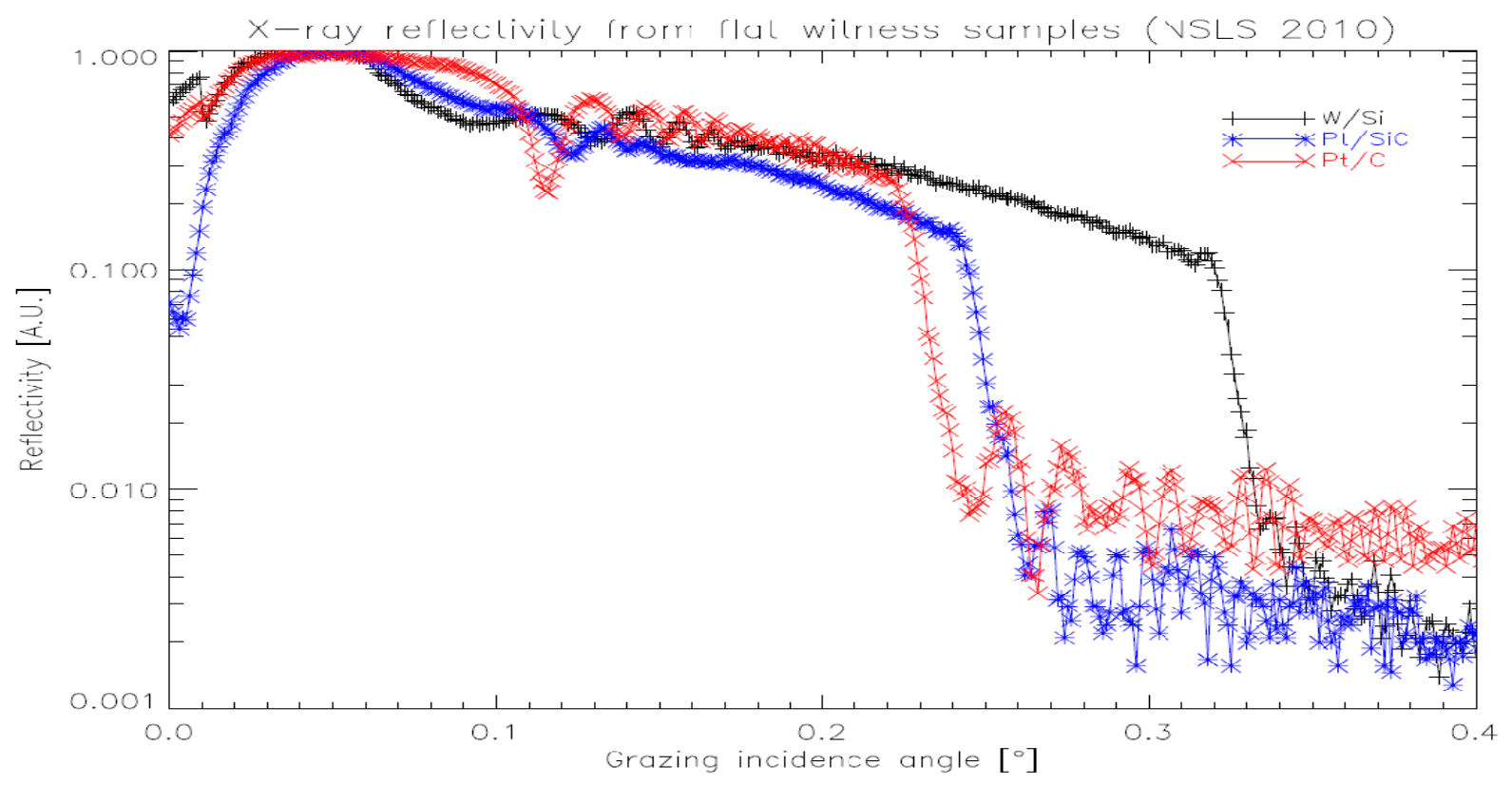

Figure 13: Reflectance data versus graze angle taken at $50 \mathrm{keV}$ at the Brookhaven synchrotron. The 3 samples are all representative of the flight coatings used for each material combination. They obviously have different minimum dspacings but apart from that it is clear that the $\mathrm{Pt} / \mathrm{SiC}$ does not perform as well as the $\mathrm{Pt} / \mathrm{C}$ and $\mathrm{W} / \mathrm{Si}$.

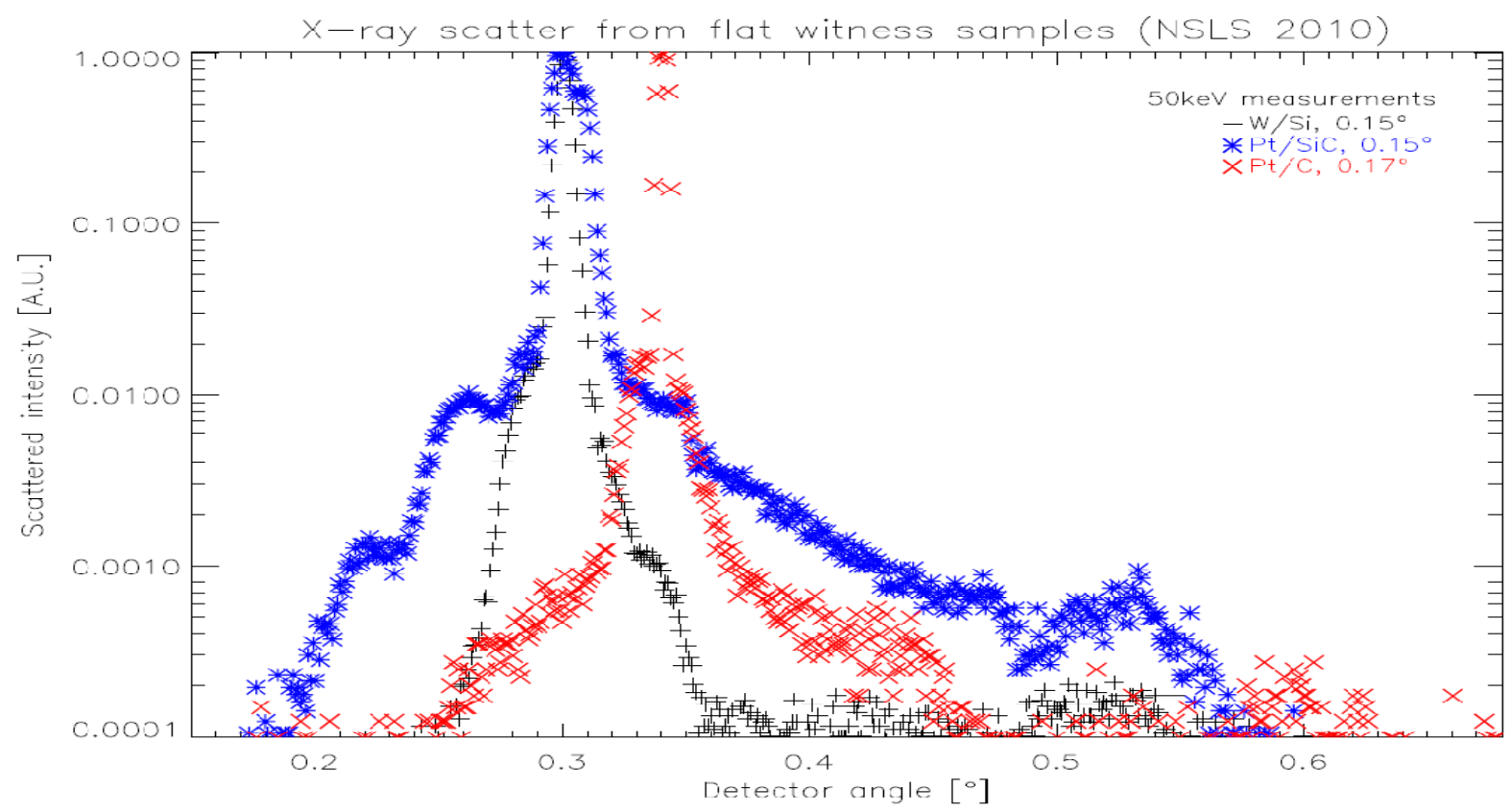

Figure 14: Scatter data from the same samples as in figure 13. The graze angle at which the scatter data are taken is indicated in the plot. Data are normalized to the peak intensity in each case. A significant scatter component is visible for the $\mathrm{Pt} / \mathrm{SiC}$ data sets whereas this is not the case for $\mathrm{W} / \mathrm{Si}$ and $\mathrm{Pt} / \mathrm{C}$. 


\section{UNIFORMITY MAPPING AND COATING STRESS}

In every coating run the Si witness sample was placed in the same position and therefore is an accurate measure of coating to coating variations as described in the previous section. Throughout the coating production we used 2-3 different coating geometries for each material combination by varying the number of bays on each mounting plate as described in the coating overview section. For each of these geometries we have mapped the coating uniformity by coating a 10 bilayer constant d-spacing coating on flight mirrors of the appropriate size. This will, to first order, provide the coating uniformity within any given coating geometry and also provide the coating thicknesses on the flight glass relative to the $\mathrm{Si}$ witness sample in its reference position. The d-spacings were measured at $8 \mathrm{keV}$ and a data set of this type are shown in figure 15, where the number in every position is the thickness relative to the witness sample. During coating the position in the coating chamber for every flight mirror was logged and likewise the position in the flight optic of every single flight mirror was logged. Combining these log files allows a detailed ray trace to implement the measured non-uniformities relative to the specific witness sample with its very accurately measured and parameterized reflectance. This work is currently under way using a ray trace tool developed at DTU-Space ${ }^{18}$. Once this detailed modeling has been fully validated and successfully used to model limited aperture data from the on ground calibration ${ }^{7}$ we will implement it in the NuSIM simulation package ${ }^{19}$.

Coating induced stress can distort free standing thin flight mirrors and it is therefore important that the coating stress is as low as possible and carefully tracked from coating to coating. To this end we placed a stress sample in every coating run and measured the stress for every coating run. Table 5 gives the average stress value obtained and the range of stresses measured for Pt/C and W/Si. Although rather low stress values were obtained they are still high enough that laser scanning after coating revealed significant stress induced bows of the free standing pieces ${ }^{7}$. These were easily removed by the mounting but it cannot be entirely excluded that a small contribution to the NuSTAR PSF remains from coating induced stress. This issue would certainly need to be addressed for optics with a significantly lower specification on HPD than that of NuSTAR. 


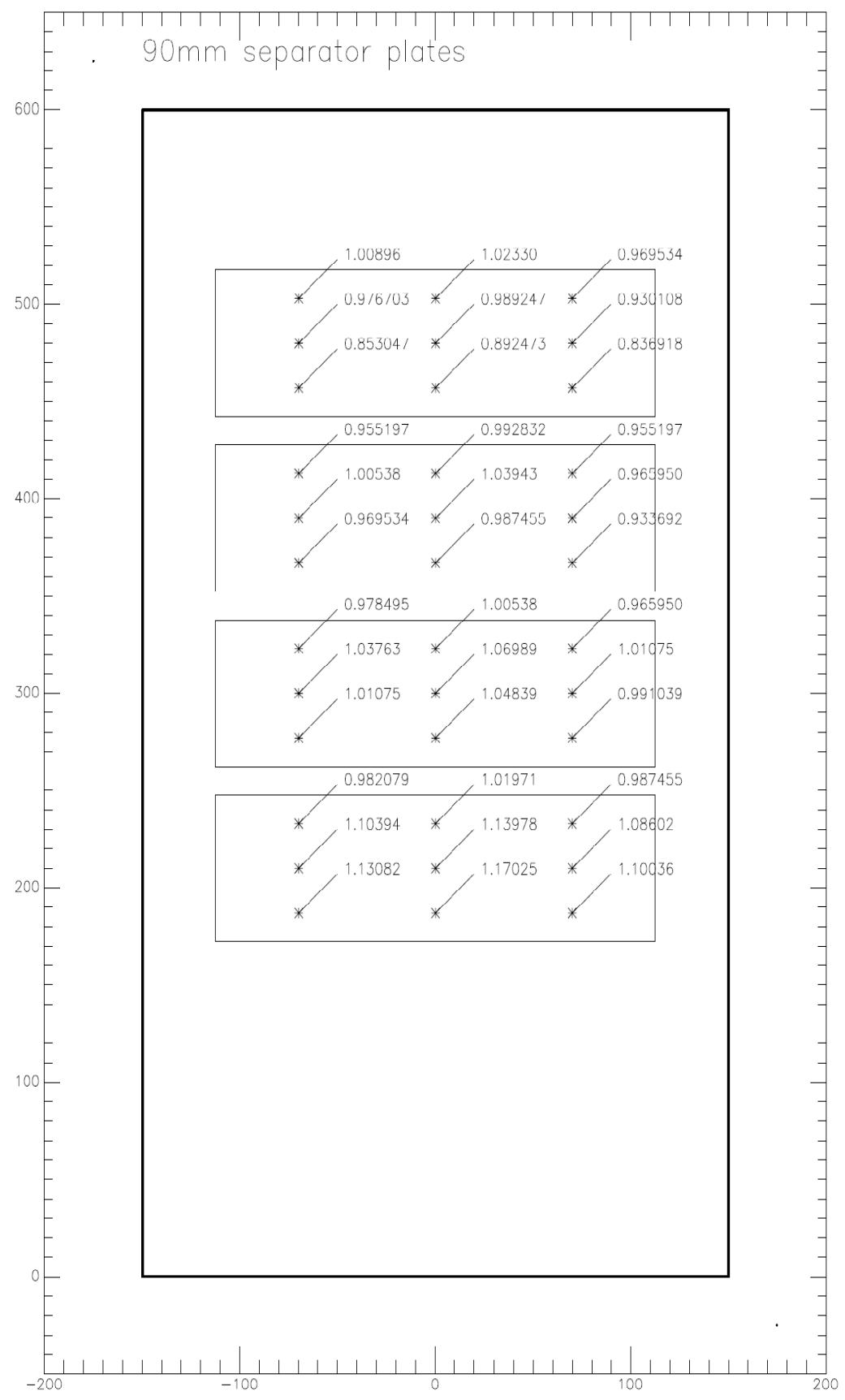

Figure 15 : Measured uniformity versus position for one of the coating geometries corresponding to the use of 4 bays per mounting plate. The Number at each point is the d-spacing relative to the Si witness sample. 
Table 5: Average and range of stresses measured for all flight coatings in the DTU facility

\begin{tabular}{|l|l|l|}
\hline Material combination & Average Compressive stress & Range \\
\hline $\mathrm{Pt} / \mathrm{C}$ & $134 \mathrm{Mpa}$ & $50-300 \mathrm{Mpa}$ \\
\hline $\mathrm{W} / \mathrm{Si}$ & $75 \mathrm{Mpa}$ & $10-200 \mathrm{Mpa}$ \\
\hline
\end{tabular}

\section{SUMMARY AND CONCLUSIONS}

The NuSTAR coating effort has been presented, including the final coating designs and detailed hard X-ray data on witness samples. These show that the NuSTAR coatings come very close to the intended designs with the anticipated interfacial roughness. The flight mirrors, however, show slightly higher roughness which is reflected in the multilayer coatings. Together with coating chamber uniformity mapping and other metrology data taken during build these data can be used directly in future ray trace efforts to provide a complete optics response model.

\section{ACKNOWLEDGEMENTS}

We gratefully acknowledge the help of Monica Fernandez-Perea, Sherry Baker and Regina Soufli for acquiring and analyzing the AFM data referred to in table 3. Likewise we gratefully acknowledge the help of Suzanne Romaine and Rick Bruni during the scatter measurement campaign at the Brookhaven synchrotron. We also want to thank Doug Thornhill, Clio Sleator and Shuo Zhang for help in taking the data on the hundreds of Si-witness samples at the RaMCaF facility. Finally we thank Simone J. Jakobsen, Mettte Friis, Nis B. Andreasen and Joachim Mortensen for assistance in the day to day maintenance and operation of the coating facility.

\section{REFERENCES}

[1] Harrison F.A., Christensen F.E., Craig W.W., Hailey C.J., Baumgartner W., Chen C.M.H., Chonko J., Cook W.R., Koglin J., Madsen K.K., Pivavoroff M.J., Boggs S.,Smith D., "HEFT and NuSTAR focusing telescopes", Experimental Astronomy, Volume 20, Issue 1-3 (2005) 131-137.

[2] Harrison F.A., Boggs S., Christensen F.E., Craig W.W., Hailey C.J., Stern D., “The Nuclear Spectroscopic Telescope Array (NuSTAR)", Proc, SPIE 7732 (2010).

[3] Christensen F.E., Hornstrup A.,Westergaard N.J., Schnopper H.W., Wood J., Parker K., "A graded d-spacing multilayer telescope for high energy X-Ray Astronomy", Proc, SPIE 1546(1991)

[4] Hailey C.J., Abdali S., Christensen F.E., Craig W.W., Decker T.A., Harrison F.A., Jimenez-Garate M.A., "Investigation of substrates and mounting techniques for the High Energy Focusing Telescope (HEFT)", Proc. SPIE 3114, (1997).

[5] Craig W.W., Hailey C.J., Christensen F.E., Jiminez-Garate, M.A.,Windt D.L., Harrison F.A., Mao P.H., Hussain A., "Development of thermally formed glass optics for astronomical hard X-ray telescopes", OPTICS EXPRESS, Volume 7(4), 178-185,(2000)

[6] Brejnholt N.F., Christensen F.E., Jakobsen A.C., Hailey C.J., Koglin J., Blaedel K.L., Stern M., Thornhill D., Sleator C., Xhang S.,Craig W.W., Madsen K.K., Decker T.A., Pivovaroff M.J., Vogel J., "NuSTAR ground calibration : The Rainwater Memorial Calibration Facility (RaMCaF)", These proceedings ( 8147-16) (2011). 
[7] Koglin J., An H.J. Barriere N., Brejnholt N.F., Christensen F.E., Craig W.W., Hailey, C.J. .Jakobsen A.C., Madsen K.K., Mori K., Nynka M., Pivovaroff M.J. Ptak A., Thornhill D., Vogel J., Wik D., Zhang W.W., "First results from the ground calibration of the NuSTAR flight optics", These Proceedings (8147-17) (2011)

[8] Craig W.W., An H.J., Blaedel K.L., Christensen F.E., Decker T.A., Fabricant A.M., Gumm J., Hailey C.J., Hale L, Koglin J., Mori K.,Nynka M., Pivovaroff M.J., Sharpe M.V., Stern M.,Tajiri G., Zhang W.W., "Fabrication of the NuSTAR Flight Optics", These proceedings. (8147-45) (2011).

[9].Koglin J., An H.J., Blaedel K.L., Brejnholt N.F., Christensen F.E., Craig W.W., Decker T.A., Hailey C.J., Hale L., Harrison F.A., Jensen C.P., Madsen K.K., Mori K., Pivovaroff M.J., Tajiri G., ZhangW.W., "NuSTAR hard X-ray optics design and performance", Proc, SPIE 7437(2009)

[10] Madsen K.K., Harrison F.A., Mao P.H., Christensen P.H., Jensen C.P., Brejnholt N.F.,Koglin J., Pivovaroff M.J., "Optimization of Pt/SiC and W/Si multilayers for the Nuclear Spectroscopic Telescope Array", Proc. SPIE 7437 (2009).

[11] Windt D.L., Waskiewicz W.K. "Multilayer facilities required for extreme-ultraviolet lithography”, J. Vac. Sci. Technol. B, 12, 3826 - 3832 (1994)

[12] Jensen C.P., Madsen K.K., Christensen F.E., "Investigation of new material combinations for hard X-ray telescope designs" Proc, SPIE 6266(2006)

[13] Vickery A., Jensen C.P., Christensen F.E., Steenstrup M.P., Schønfeldt T., "Collimated Magnetron Sputter Deposition for Mirror Coatings", Journal of X-Ray Optics and Instrumentation, Volume 2008, Article ID 792540(2008)

[14] Christensen F.E., Abdali S. , Hornstrup A., Schnopper H.W., Slane P., Romaine S.E., "High resolution X-Ray scatter and reflectivity of sputtered Ir surfaces", Proc, SPIE 2011(1993)

[15] Mao P.H., Harrison F.A., Windt D.L., Christensen F.E., "Optimization of graded multilayer designs for Astronomical X-ray telescopes”, Applied Optics, Volume 28(22) (1999)

[16] Zhang W.W., "Fabrication of glass mirror segments for the International X-ray Observatory", Proc, SPIE (7732) (2010) .

[17] Fernandez-Perea M., Baker S., Soufli R., Pivovaroff M.J., - Work in progress

[18] Westergaard N.J.,"MT_RAYOR : A versatile ray tracing tool for X-ray telescopes”, These proceedings,(8147-64) (2011)

[19] Madsen K.K., To be published 